\title{
Study on Popularization and Application of Bamboo in Interior Design of Chinese Architecture
}

\author{
Zhang Xiang*, Wang Chenchao \\ Department of Urban Construction, Chongqing Technology \& Business Institute, Chongqing, China
}

\section{Email address:}

619339136@qq.com (Zhang Xiang), 1301804615@qq.com (Wang Chenchao)

${ }^{*}$ Corresponding author

\section{To cite this article:}

Zhang Xiang, Wang Chenchao. Study on Popularization and Application of Bamboo in Interior Design of Chinese Architecture. Science Discovery. Vol. 5, No. 7, 2017, pp. 561-564. doi: 10.11648/j.sd.20170507.25

Received: November 15, 2017; Accepted: November 23, 2017; Published: December 29, 2017

\begin{abstract}
This paper analyzed the advantages of bamboo from the perspective of interior design, summarized the application and ecological value of bamboo, and explored the feasibility and method of applying bamboo in modern interior design of China. It aimed to popularize the use of bamboo in interior design of Chinese Architecture. Finally, we can achieve the purpose of saving resources and protecting the environment by substituting bamboo for wood and substituting bamboo for steel.
\end{abstract}

Keywords: Bamboo, Interior Design, Application Value, Ecological Value, Application Mode

\section{中国竹材在建筑室内设计中的推广应用研究}

\section{张翔“，王晨超}

城市建设工程学院, 重庆工商职业学院, 重庆, 中国

邮箱

619339136@qq.com（张翔）, 1301804615@qq.com（王晨超）

摘要：文章从室内设计的视角分析了竹材的优点，在此基础上总结了竹材的应用价值和生态价值，并探讨了中国现代 室内设计中应用竹材的可行性和方式方法。旨在推广竹材在中国建筑室内设计中的普及运用, 从而做到以竹代木、以 竹代钢，节约资源，保护环境。

关键词：竹材, 室内设计, 应用价值, 生态价值, 应用方式

\section{1. 引言}

中国使用竹子的历史久远, 竹子的运用渗透到人们衣 食住行的各个方面, 并形成丰富多彩、独具特色的中国竹 文化。从古至今，名人骚客咏竹的诗文不计其数，“宁可 食无肉，不可居无竹”，“松、竹、梅，岁寒三友”，“梅、 兰、竹、菊四君子”，这些文字都反映了竹子与中国人民 生活、文化的密切关联[1]。
而竹材作为一种建筑材料, 古今中外都得以广泛使 用。虽然现代建筑的结构与装饰材料使用上, 钢材、水 泥、玻璃等占据了主流, 但今天随着都市人们田园情结 的回归, 并大力倡导绿色发展, 竹材的属性完全顺应了 潮流发展, 加上设计师不遗余力地探索, 使得竹材作为 设计材料的运用有了越来越多的亮点。

2016年5月4-6日, 由美国匹兹堡大学、英国考文垂大 学以及国际竹藤组织 (INBAR) 联合主办的“城市环境中 的竹结构” (Bamboo in the Urban Environment) 国际研讨 会在匹兹堡大学召开, 会议的主题为讨论并推进竹结构标 
准化, 审议国际标准化组织ISO的原竹建筑标准, 交流竹 材加工及工程应用的科研和工程进展, 促进竹材在城市建 设中的应用和相关研究。研讨会后发布了《匹兹堡宣言》, 宣言呼吁全球采取行动, 提高对竹子效益的国际认可, 并 为更有效地利用竹子作为建筑材料提出建议[2]。

传统的室内设计中，木材作为一种主要材料被大量使 用, 但木材成材周期长, 对木材的过度采伐导致了森林面 积逐年减少, 森林资源和生态环境破坏严重。而竹子生长 周期短、再生性强, 并有着诸多优良的使用性能。所以, “以竹代木”, 思考竹材在室内设计中的推广应用方式, 具 有很高的生态价值和设计价值。

\section{2. 中国竹资源概况}

中国是世界上竹类资源最为丰富、竹林面积最大、开 发利用竹资源最早的国家之一，素有“竹子王国”之称。中 国有竹类植物 39 属, 500多种, 占世界竹林总面积近 $1 / 4$ 。

在中国, 竹子主产于秦岭、淮河流域以南地区, 北起 河南桐柏山的南端和大别山的北坡, 南抵海南南端, 西自 西藏错那的雅鲁藏布江下游-四川盆地南缘, 东迄浙江-福 建沿海和台湾西部低山丘陵, 相当于北纬 $18^{\circ} \sim 38^{\circ}$ 、东经

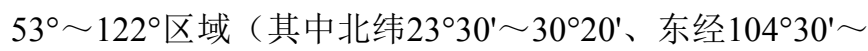
$122^{\circ} 00^{\prime}$ 为主要区域), 竹资源自然分布范围极广。大面积 的竹林主要分布在中国东西南20多个省区, 有福建、广东、 广西、贵州、四川、江西、浙江、湖南、湖北、安徽、江 苏等省（自治区），其中北纬 $23^{\circ} \sim 30^{\circ}$ 、东经 $100^{\circ} \sim 122^{\circ}$ 间的毛竹面积分布大约占全国毛竹面积的 $70 \%$ 以上, 是中 国主要毛竹自然分布的中心区域, 尤以江西、福建、湖南、 浙江、广东、云南等省份面积最大。

中国按气候性和区域性可分为五大竹林区域:一为北 方散生竹区; 二为江南混合竹区; 三为西南高山竹区; 四 为南方从林竹区; 五为琼州攀援竹区。在这些省区, 竹林 生长在平原、盆地、山地、丘陵、高原（海拔 $800 \mathrm{~mm}$ ) 等 地域带, 其土质均呈微酸性, PH值为4.5 7.0; 其气候温 暖, 多雨湿润, 土壤适宜。竹子生长正需要“也宜阴雨也 宜晴”的气候, 所以中国东西南地区最适宜栽培和生长竹 类植物[3]。

2009-2013年第八次全国森林资源清查结果显示, 中 国竹林面积共601万公顷，其中，2013年全国竹材产量 18. 77 亿根, 为中国工农业生产和文化事业的发展提供 了大量的原料。中国毛竹林面积约占全国竹林总面积的 $60 \%$, 而福建、浙江、江西、湖南四省的毛竹林面积约 占全国毛竹林面积的 $80 \%$ 。

\section{3. 竹子作为建筑与装饰材料的优点}

竹材拥有诸多优良性能和特点, 这些优点是竹材能作 为建筑与装饰材料原材料的前提, 是其价值体现的物质基 础。

（1）取材方便：竹子适应性强, 易繁殖、易栽种。 在中国南方, 竹资源丰富, 取材方便。
（2）易加工：天然竹材的纤维分布方向和密度要比 木材有规律, 这个特性使得竹材比木材在加工时更易掌握 和操作。

（3）韧性好: 竹子抗弯强度较高, 具有比较明显的 弹性。在相同的密度条件下, 竹材所具有的弯曲度、挠度 都大大超越了木材, 所以竹材作为结构构件在韧性和抗震 性上要优于木材。

（4）强度高：尽管竹子很轻, 但它是世界上最坚硬 的植物之一。从力学上讲, 竹材的强度是一般木材的两倍, 抗压强度可达 $80 \mathrm{MPa}$, 顺向抗拉强度为 $200 \mathrm{MPa}$ 。从数据 来看, 竹材的抗压性约等于砖头和水泥, 抗拉性甚至可以 和钢材相媲美 [4]。

（5）耐久性较好: 竹材和木材在化学成分上极其相 似, 都是由纤维素和木质素组成的“天然复合材料”, 而纤 维素和木质素又都是有机高分子聚合物, 所以在一定的物 理条件下竹材具有很好的耐久性。经过适当处理的竹材, 使用寿命可达 30 年之久。中国古建筑中常用到的竹条、竹 钉、竹骨等部件, 保存完好的能达到两三百年的历史。

（6）舒适性：因为竹子能够自主调节空气中的湿度 比例, 而且竹子的导热系数也比较低, 所以具有冬暖夏凉 的优良特性。

\section{4. 竹材在建筑室内设计中的应用价值}

\section{1. 经济价值}

竹子生长周期短、产品多元化、投资风险小、市场潜 力大。第八次全国森林资源清查结果显示, 2013年中国竹 业总产值1670.75亿元。随着技术的进步和经济的发展, 竹产业从过去的以农业为主, 发展到现在的建筑业、造纸 业、加工业等多个行业, 还可以同时发展生态文化旅游业。 在林业建设中，竹子可谓“慢中之快”, 在科学经营下, 竹 子只需3 4年便可以产笋和采伐利用, 相比较木材一般 10 20年才能成材要快得多, 而且竹子一次造林可上百年 连年收获, 较松、杉等大部分林木综合效益高许多。发展 竹产业成为发展山区经济、帮助农民脱贫致富的新途径。

全世界每年生产的竹材, 用于建筑的占 $30 \%-40 \%$, 竹 制品占 $15 \%$, 造纸占 $20 \%-50 \%$, 其他方面占 $15 \%-30 \%$ 。竹 建筑技术最重要的优点是成本低廉但不降低建筑质量, 而 且经久耐用。根据哥斯达黎加PNB的统计, 竹房屋比普通 材料住宅的成本便宜 $20 \%$ 。竹材在建筑室内设计中可以运 用的方面很多, 主要体现在: 竹制地板、竹制装饰板材、 竹制家具、竹制工艺陈设品、竹制灯具、竹制墙纸、竹子 景观等。只要对竹资源加以合理开发利用, 竹材就会成为 新兴的建筑装饰材料[5]。

\section{2. 生态价值}

20 世纪, 在全世界经济高速发展的同时, 森林资源也 遭到了空前的破坏。21世纪，人们必须合理地协调解决人 类资源、环境和发展之间的关系，走可持续发展的道路。

竹资源具有一次造林成功即可连年采伐利用的特点, 并具有固土、固碳、涵水、节能等生态功能。竹类植物地 下茎根系统发达, 固土能力是马尾松林的 1.5 倍。竹林的 
固碳释氧能力十分巨大[6], 甚至远超亚热带的其他林木, 每公顷毛竹的年固碳量为5.09吨, 是热带雨林的1.33倍, 同等面积的竹林较树林可多释放 $35 \%$ 的氧气。竹林冠层枝 叶茂盛, 枯枝落叶层较厚, 具有极强的截留降水能力, 每 公顷竹林可蓄水1000吨。竹材也具有优异的节能性, 研究 表明: 建造相同面积的建筑, 竹子的能耗是混凝土能耗的 $1 / 8$, 是木材能耗的 $1 / 3$, 是钢铁能耗的 $1 / 50[7]$ 。

所以，随着技术的不断开发与成熟，在建筑与室内设 计中, 大量应用竹子作为建筑装饰材料, 以竹代木、以竹 代钢, 必将有效缓解木材等资源紧缺的现状, 并取得良好 的生态效益和社会效益。

\section{3. 审美价值}

竹材不论是作为景观的整株形态, 还是作为结构的竹 竿材, 抑或是竹子进行横坚剖切制成的各种材料, 都具有 其各自的审美特征。

\subsection{1. 形态美}

竹子是梅、兰、竹、菊“四君子”之一，四季常绿、赏 心悦目, 自古以来就是建筑室内外不可或缺的景观植物。 竹子姿态优美, 除了竹笋的挺拔向上、竹竿的高大挺直、 竹枝的凌空横展、竹叶的邚娜多姿, 还有随着季节的变换, 竹景也随之变化, 春之动、夏之荫、秋之爽、冬之静展露 无遗, 出笋时的生命感、抽条时的线条感、展叶时的伸展 感、换叶时的萧瑟感, 都是竹子形态美的具体体现。

\subsection{2. 色彩美}

竹材的天然竿色可以分为两种: 一种是竹材刚采伐时 的竹青所保持的绿色系色彩, 另一种是竹材采伐自然放置 一段时间之后，竹青的绿色退去而变为黄色系色彩。竹材 中, 暖色调的浅黄色到黄褐色会给人以温暖、靠近之感, 而竹子的绿色能给人带来安宁、平静、生命、希望的心理 感受, 缔造出产品清新自然的风格。

\section{3.3. 肌理美}

竹材纹理通直, 相比木材, 竹材的天然纹理也极具形 式美, 无论纵切、横切, 竹材的切纹都很自然、生动、流 畅, 这一点也是竹材千百年来受人们欢迎的重要原因。竹 子的表皮即竹青组织紧密、质地坚韧, 表面光滑平整, 光 泽度高, 同时竹材吸热性和吸湿性都优于木材, 因此, 竹 材的天然表皮肌理能够给人坚硬、干净、清爽的质感。竹 材不同的剖切方式, 能给竹材切面带来不同的肌理效果, 纵向平行而细密排列的竹纤维, 疏松脆弱, 呈淡黄色, 纹 理一致, 清晰简明; 横断面上呈现出排列整齐的深色斑点, 点的形态细密、肌理感强。

\subsection{4. 结构美}

竹竿材作为结构的组成部分, 具有相应的结构美。相 比木材的结构美, 竹材在细节上虽然比不上木材榫卯结构 的精细, 但是也有其独特的韵味, 各种捆扎、穿插、聚散 使得细节上精细而不繁杂。竹材相较于钢材、木材运用于 结构中的一个极大优势就是其挠度大, 可以进行弯曲, 弯 曲后排列的韵律是其他材料所无法比拟的, 而且弯曲后,
运用于大跨度的拱中, 既是结构又是装饰, 本身的结构美 代替了装饰美。相对于常见的钢桁架结构, 竹材因其特殊 的颜色, 给人以亲和感, 显得结构更为轻盈, 原始的材料 使得这种桁架给人一种回归自然的感受。

\section{5. 竹材在建筑室内设计中的应用方式探讨}

千百年来，竹材利用长期停留在原竹利用、䢃揽编 织等经过简单的粗加工生产初级产品。近些年中国在竹 材工业性开发利用方面取得了很大进展, 涌现出许多科 技含量较高的装饰系列产品。中国竹产区应充分利用优 势条件, 大力开发竹质建筑材料与产品, 并将其与中国 竹文化结合, 推广运用于室内设计中, 既能产生生态价 值和经济价值, 更能体现浓厚的中国本土设计特征。下 面从室内空间的主要组成元素来归类, 探讨竹制产品在 室内设计中的运用方式。

\section{1. 室内界面装饰材料}

\subsection{1. 竹质板材}

竹质板材在室内设计中的运用, 除了粗加工的天然竹 材产品外, 更应该研制开发符合各类设计需要的竹质人造 板材。竹质人造板材一般经过选材、制材、漂白、硫化、 脱水、防虫、防腐、热固胶合等工序加工而成，已经开发 运用较多的有竹编胶合板、竹材胶合板、竹䒼层压板、竹 地板、竹木复合板等产品[8]。竹质板材在室内界面装饰中, 可以作为天花板、墙柱饰面板、门板、地板等使用。室内 界面、隔断、门窗等造型设计上, 我们可以将中国的地域 文化元素按照现代审美要求进行重构和整理, 以竹材为载 体进行充分表达, 具有浓厚亲切的地域风格。竹质板材具 有外观优美、冬暖夏凉、经久耐用等优点 [9]。

\subsection{2. 竹质壁纸}

现阶段，竹质壁纸根据加工方式可分为两种类型:

（1）将竹子原料制成竹浆后再加工成壁纸。竹纤维 细淢并有很好的柔软度, 竹浆制成的壁纸表面富有弹性, 舒张厚实, 有较高的机械强度, 隔音、隔热、保温性能好, 手感柔软舒适。

（2）将竹子处理成策片结构, 采用传统工艺手工编 织而成。这种壁纸表面有上清漆、不上漆或者碳化出来的, 表面质感和立体感显著, 色调高雅, 其特别之处在于具有 一定的视觉不均匀性和轻度色差, 自然纯朴, 粗犷豪放。

\section{2. 家具}

竹制家具具有浓郁亲切的乡土气息, 尤其在中国江南 地区使用十分普遍, 其造型简洁、质朴淡雅、舒适凉爽。 传统竹家具包括竹登、竹椅、竹桌、竹柜、竹床、竹茶几 等各种日常用具。但由于当时的制作工艺水平低下，竹家 具质量和款式都有限, 容易出现虫蛙、开裂甚至腐烂等问 题。

竹材与木材相比较, 具有强度高、韧性好、硬度大 等特点。随着竹材工业化开发利用的技术创新, 竹材经 过高温蒸煮杀菌, 加上现代防腐、防蛙等技术处理, 含 
水率的控制, 有效控制竹家具的开裂和变形, 可以使竹 制家具的结构、造型更为多样化和艺术化。竹制家具可 以制成圆竹家具、竹集成板家具、薄板贴面家具及胶合 板家具还有传统的竹覧编织等类型。通过对于地域文化 元素的抽象提取, 将其融入竹制家具的造型和外观设计 中, 既富有民族传统韵味, 又满足现代审美、舒适方便 的功能要求, 完全可以替代木制家具 [10]。

\section{3. 灯具}

竹艺灯饰其实在中国历史悠久。随着现代竹材加工技 术的深入开发, 电源连接和电子元件及各种零部件的发明 创造, 给竹艺灯具的设计带来更多的形式和可能性。竹艺 灯具, 在设计上可以加入中国传统风格的元素, 从材料和 形式上充分体现地域特色; 也可以采用现代设计中的简约 手法, 既体现现代审美习惯, 又难掩材料本身带给我们的 自然气息[11]。竹艺灯具可以制成的种类品种繁多，包括 市面上的各种类型的灯具, 如吸顶灯、台灯、吊灯、壁灯、 筒灯等。竹艺灯具表面色彩的处理也可以做成原竹色、碳 化色和做漆上色。传统与现代的碰撞, 技术与艺术的交融, 让竹艺灯具在灯具市场上定会占有重要的一席, 有人就曾 这样评价竹艺灯的价值: “它虽不是主流, 但至少是独特。”

\section{4. 工艺陈设品}

竹工艺品在中国已经历了数千年的历史，独具特色。 传统竹工艺品按制作工艺不同主要可分为竹编工艺品及 竹雕刻工艺品两大类。

竹编工艺品将竹子䢃成藿片, 用以编织各种精美的用 品及装饰品, 从传统的篮、盘、罐、盒发展到屏风、动物、 人物、装饰等诸多产品。中国川渝地区盛产慈竹, 富有弹 性, 很适于编织。例如梁平竹窝可称巴蜀竹编工艺中的一 绝, 它采用色泽柔和的慈竹细竹丝为纬线, 每尺竹帘用竹 丝800至 1000 根, 编织的竹窝精致平整、画面精美。其他 的竹编工艺品包括竹席、字画、睡席、沙发套、竹枕等品 种, 图案丰富, 山水人物、古今字画、翎毛花卉等, 均能 编制得惟妙惟肖、栩栩如生。

竹雕刻工艺品也是一种独特的传统工艺, 艺人们利用 竹根、竹节等自然形态, 在竹筒、竹片、竹根上雕刻成山 水、亭台楼阁、人物花草等各种艺术造型, 艺术家们可根 据竹材不同的形状和部位采用圆雕、透雕、浮雕等不同的 雕刻技法，作品自然天成、品位高雅。

随着现代竹材加工技术的发展, 可以在继承传统竹工 艺品制作技艺的基础上, 一方面采用新型的人造竹材, 另 一方面集成中国传统与现代文化元素, 创作更多富有中式 特色的竹制工艺陈设品, 点缀建筑室内空间[12]。

\section{5. 室内外景观}

竹挺拔秀美、常年青翠，更具摇曳之姿和清疏之影， 能使人涤荡尘念、畅神怡目, 同时还能体现人文气质和地 域特征, 是营造室内外景观非常理想的素材。室内空间中, 竹的引入能使空间丰富而且立刻活跃起来。同时竹还可以 作为分隔、限定室内空间的元素, 比用实体建筑材料划分 的空间更具有人情味, 空间的意趣也更强。因竹子植于室
外较为常见, 室内的竹景观常常会给人室外空间的暗喻, 同时, 我们可采用借景的手法, 将室外的竹景“借”到室内, 使室外自然景观被纳入室内观赏者的特定视野, 从而使人 模糊室内外的空间界限, 产生开阔的心理感受。

\section{6. 结论}

虽然竹材在中国建筑及其室内相关物品中的运用历 史久远, 但其过去运用的方式比较粗放, 而且运用范围 也还不够普遍。在能源和资源集约使用的今天, 我们的 科技水平完全可以对竹材的精细利用进行深入的研发, 制造出以竹材为原料的各种新型建筑材料和制品, 加以 推广利用, 结合现代审美方向探讨其在室内设计中的运 用方式, 并大面积地取代木材和钢材等传统建筑材料, 让竹材成为中国主流建筑材料, 从而达到节约资源、保 护环境的目的。

\section{参考文献}

[1] 何明, 廖国强. 中国竹文化[M]. 北京：人民出版社，2007

[2] 竹子作为新型建筑材料的(匹兹堡宣言) [J]. 世界竹藤通讯, 2016,14(4):47〜 48

[3] 谢左章, 陈策. 竹子 [M]. 广州: 广东科技出版社, 2009

[4] 尹维, 田显, 陶大帅, 等. 天然树木和竹子纤维材料的力学 性能及仿生研究进展. 科学通报, 2015,60(31):2949 2962

[5] 石红青, 张君颖. 近年来中国林业科学研究热点及趋势 基于 2005 年-2015年《林业科学》期刊关键词的共词分析 [J]. 农业图书情报学刊，2017，29(2):94～102

[6] 余勇. 竹建筑的环保“能量”[J]. 环境, 2009(9):54 56

[7] 陈笚舟. 竹资源在环境艺术设计中的运用 [D]. 重庆: 西南大 学, 2013:9

[8] 张世源. 竹纤维及其产品加工技术[M]. 北京: 中国纺织出版 社, 2008

[9] 周艳. 竹材料在室内设计中的应用研究[D]. 合肥: 安徽建筑 大学, 2015:17

[10] 潘若琳. 竹制品的应用及其创新设计方法研究 [D]. 长沙: 中 南林业科技大学，2011:59

[11] 夏波. 基于竹文化的现代家居产品设计开发研究 $[\mathrm{J}]$. 北方文 学(下旬), 2016(11):165

[12] 周媛. 新东方主义建筑室内设计实践研究[D]. 沈阳: 沈阳建 筑大学, 2011:8

[13] (西)爱德华.布鲁托. 竹材建筑与设计集成[M]. 张振东, 译. 南京: 江苏凤凰科学技术出版社, 2014

[14] 王爱民，李新国. 中国2010年世界博览会“竹藤元素场馆” 剖析[J]. 世界竹藤通讯，2011(1):41 44 